\title{
Applications of Geo-Referenced
}

\section{Underwater Photo Mosaics in Marine Biology and Archaeology}

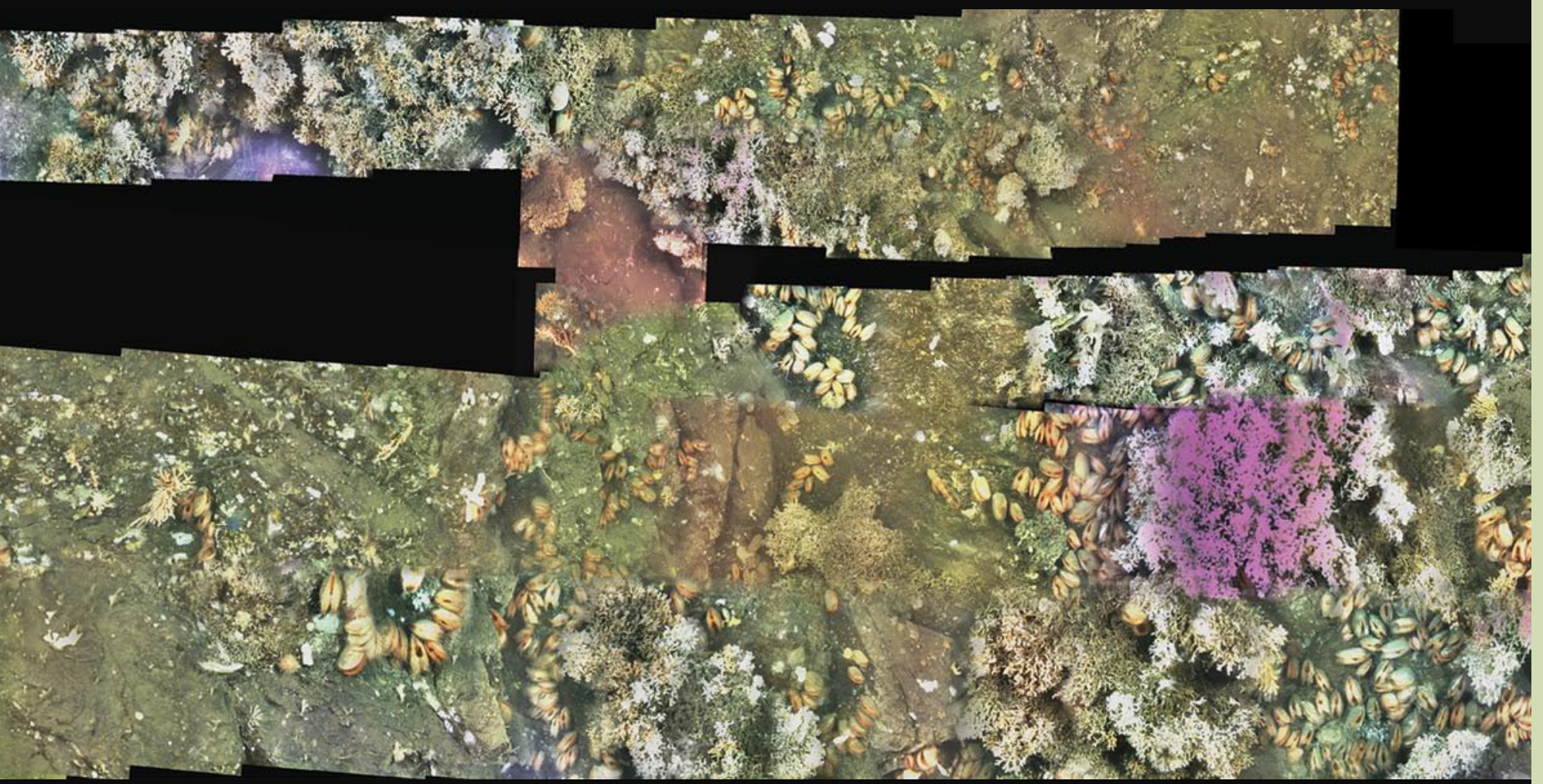

BY MARTIN LUDVIGSEN, BJ ØRN SORTLAND, GEIR JOHNSEN, AND HANUMANT SINGH

IN DEEP WATER, below the photic zone, still and video imaging of the seabed requires artificial lighting. Light absorption and backscatter caused by typical seawater components, such as dissolved organic matter, plankton, and inorganic particles, often limit the artificially lit area to a few square meters. To obtain high-resolution photographic data of larger seabed areas, a series of images can be compiled into a photo mosaic. Image mosaics are easier to interpret, communicate, and exhibit than video footage or a series of images, because the individual image frames in a photo mosaic are naturally represented in a spatial context.
The ideal photo mosaic should provide an overview of the area of interest and the distribution, size, position, and orientation of the objects found. The final result should include all the details captured in the initial images. Marine archaeologists and biologists are typical users of this technology. The information provided by a photo mosaic can help archaeologists reconstruct the sequence of events that formed the features in an underwater investigation site. In marine biology, photo mosaics can be used to document habitats by identifying morphological characteristics of present taxa (e.g., size and color), density, area coverage, substrate, and interactions between individuals. 
Beginning in the 1960s, underwater photo mosaics were produced by physically stitching images together to create new images from the arrangements of individual picture frames. One of the first examples of underwater photo mosaics in the literature shows the sunken submarine Thresher (Ballard, 1975). The photo mosaic of the sunken passenger ship Titanic (Ballard, 1987) is among the most famous examples. As technology progressed, specialized hardware emerged, combining two images into a new image using slides and variable projection planes. Development of the computer and digital image processing gradually led to digital production of image mosaics in the 1990s. Then, the scientific discipline of computer vision emerged, focusing on automatic information extraction from imagery. Many of the most common image mosaicking schemes were developed in a subdiscipline of computer vision called SLAM (Simultaneous Localization And Mapping) (Xu and Negahdaripour, 1997; Gracias and Santos-Victor, 2001; Vincent et al., 2003; Eustice, 2005). Successful applications of photo mosaicking include archaeological imaging by Ballard et al. (2000) and Singh et al. (2004a) as well as marine biological photo mosaics for species inventory (Singh et al., 2004b) and spectral image analysis to map the abundance of bacterial mats (Jerosh et al., 2007).

Today, high-resolution data can be used to generate a complete overview of a seascape and details of organisms, substrate, and artifacts. Likewise, high-resolution images can be used to generate three-dimensional images of objects of interest. Geo-localized and high-resolution images are important for

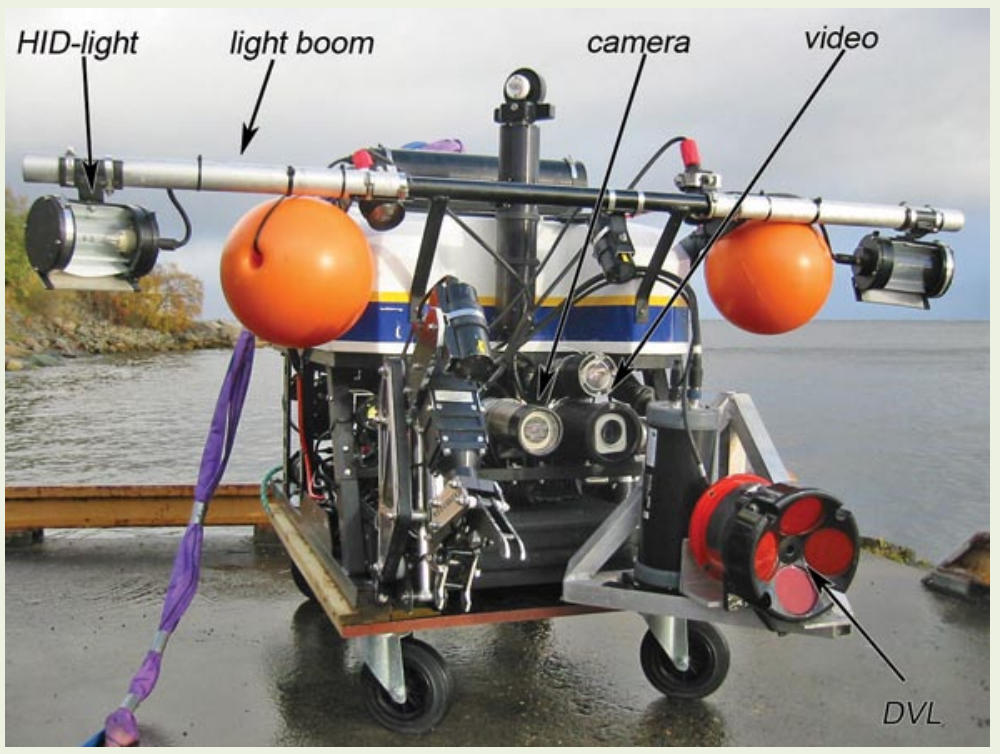

Figure 1. Configuration of the remotely operated vehicle Minerva used for image acquisition in a marine biology survey on the vertical rock wall of the fjord of Trondheim, Norway. The Doppler velocity log, high-intensity discharge lights, light booms, high dynamic range camera, and video cameras are all pointing forward.

revisits to a given site or object of interest and are very important for obtaining time series (e.g., for process-oriented and climate-related research in marine biology). We present two case examples to elucidate applications of photo mosaics in marine biology and marine archaeology. The marine biological example is part of a habitat mapping survey in the fjord of Trondheim at Stokkbergneset $\left(63^{\circ} 28^{\prime} \mathrm{N}, 9^{\circ} 54^{\prime} \mathrm{E}\right)$, approximately $20 \mathrm{~km}$ west of the city of Trondheim, Norway. The site comprises a vertical rock wall rising from $530 \mathrm{~m}$ to $200 \mathrm{~m}$ depth. The objective of the survey was to map the characteristics of benthic filter feeder communities dominated by stony corals, horny corals, and bivalves attached to the vertical wall at $250-450 \mathrm{~m}$ depth.

The archaeology photo mosaic example was made during an investigation the of the pipe line routes for the Ormen Lange gas field off Aukra $\left(62^{\circ} 4^{\prime} \mathrm{N}\right.$, $\left.6^{\circ} 54^{\prime} \mathrm{E}\right)$ in the Norwegian west coast. Norwegian cultural heritage authorities requested a marine archaeological survey of the pipeline routes for the gas field, which led to the discovery of a historical shipwreck close to the pipeline route at $170 \mathrm{~m}$ depth. The field developer was ordered to conduct a detailed investigation of the site (Søreide and Jasinski, 2005). Two of the photo mosaics resulting from this detailed investigation are presented in this study. The first covers the whole wreck site, while the second shows a condensed area at the stern of the wreck where sediment was removed to uncover historical artifacts.

\section{METHODS AND MATERIALS Underwater Vehicles}

The work at the marine biology site was carried out by an electric observation remotely operated vehicle (ROV; Sperre AS Sub-Fighter 7500; Figure 1). Its low, $\sim 400$-kg weight provided easy handling, and the ROV proved to have sufficient maneuvering and payload capacity to handle the currents on the site, despite drag on up to $650 \mathrm{~m}$ of cable. The $60-\mathrm{ft}$, twin-hull support vessel was positioned 
using the Global Positioning System

(GPS), and the location of the underwater vehicle relative to the surface vessel was measured by a super-short baseline acoustic system (Simrad HPR 300P). A Doppler velocity log (DVL; RDI Workhorse Navigator $600 \mathrm{kHz}$, Teledyne $\mathrm{RD}$ Instruments) was pointed forward.

At the marine archaeology site, an electric work-class ROV (WROV; Sperre AS Sub-Fighter 30k) was used. The WROV weighs about $1500 \mathrm{~kg}$, has a large payload capacity, and thus was considered the best possible common platform for the variety of subtasks in the archaeology project. Because variations in camera angle during image acquisition can impose errors on the mosaic, a WROV is more favorable due to better stability in pitch and roll than a smaller vehicle. A closed-loop control system enabled the vehicle to follow the desired survey track automatically, resulting in more stable heading, speed, and seabed altitude than can be achieved by manual control. The WROV was positioned by a long-baseline acoustical positioning system aided by a DVL (RDI Workhorse $1200 \mathrm{KHz}$, Teledyne RD Instruments).

An excavation support frame placed on the wreck site (Figure 2) enhanced the stability and maneuvering of the WROV during sediment excavation and image acquisition. The $10 \times 10-\mathrm{m}$ frame was leveled by ROV-operated jacks in all four corners. When the vehicle was docking into the support frame, it was kept rotationally and vertically steady. The WROV was moved in $\mathrm{x}$ and $\mathrm{y}$ directions by rack rails and gear motors, as described by Søreide and Jasinski (2005).

\section{Camera and Light Configuration}

In both surveys, constant lighting from two 400-W HID (High Intensity Discharge; OSRAM HMI) lights were used. One wide-beam light source was placed on either side of the camera to illuminate the image-frame area as evenly as possible. On the observation

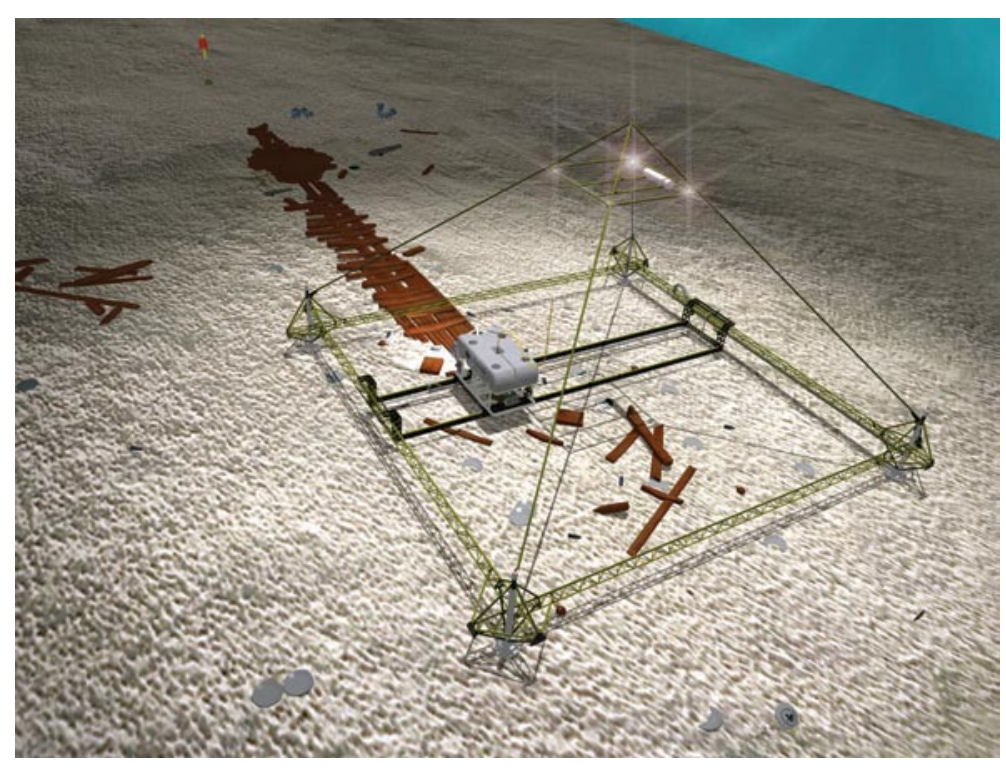

Figure 2. The excavation support frame placed over the aft part of a shipwreck during a marine archaeology survey in the Ormen Lange gas field off Aukra on the Norwegian west coast. The frame, leveled by jacks in each corner, is used to stabilize the workclass ROV during image acquisition. Figure provided by Fredrik Søreide
ROV, the lights were mounted on booms to increase the lateral distance between light source and camera, with the aim of reducing backscatter light to the camera (see Figure 1). The lateral distance between the camera and light source was approximately $0.8 \mathrm{~m}$. On the WROV, a lateral separation of light sources and camera of $0.7 \mathrm{~m}$ was obtained without light booms.

During the marine biological survey, the camera was mounted on the underwater vehicle with a horizontal image axis (i.e., aiming orthogonally at the rock wall). For the marine archaeological survey, the camera pointed downward, again imaging its target, the seabed, orthogonally. The camera used in both projects was a 12-bit dynamic range camera (Uniqvision) that captures one image every four seconds.

\section{Survey Track Design}

Optimal image overlap, sidelap, seabed resolution, and acquisition efficiency are essential to mosaic quality. They are achieved by carefully choosing proper altitude, line spacing, and velocity when planning the survey. The term "over-

MARTIN LUDVIGSEN (martinl@ntnu.no) is Ph.D. candidate, Department of Marine Technology, Norwegian University of Science and Technology, Trondheim, Norway. BJØRN SORTLAND is Associate Professor, Department of Marine Technology, Norwegian University of Science and Technology, Trondheim, Norway. GEIR JOHNSEN is Professor, Department of Biology, Norwegian University of Science and Technology, Trondheim, Norway. HANUMANT SINGH is Associate Scientist, Applied Ocean Physics and Engineering Department, Woods Hole Oceanographic Institution, Woods Hole, MA, USA. 
lap" is used for the common area in two images taken sequentially while the camera moves along a line, and "sidelap" denotes the common area of two images across track. The area covered by each image directly depends on the altitude of the vehicle and the camera's fieldof-view angle. A general recommendation for mosaics of aerial photography is to use $50 \%$ overlap and $25 \%$ sidelap. Practice has shown that this trade-off between redundant image points in image pairs and the need for effective data acquisition is also reasonable for underwater photo mosaics.

A $45^{\circ}$ field of view was used in all data-acquisition operations described in this paper. This narrow field of view produces low obliqueness in images. Apart from the available propulsion power on the underwater vehicle, the survey speed is limited by the overlap constraint, covered area, and how often it is possible to take images during data acquisition. The potential for motion blur in the images captured was not considered when the theoretical speed was calculated.

\section{Marine Biological Survey}

During data acquisition for the marine biological study, the ROV followed horizontal paths along a vertical wall, with each path one meter shallower than the previous one, so that the rock wall was covered in a back-and-forth pattern similar to mowing a lawn. The ROV heading was kept constant so that the cameras always pointed toward the wall while the vehicle moved sideways.

The distance from the camera to the seafloor or wall target was approximately $2 \mathrm{~m}$. This resulted in a coverage area of $2.3 \mathrm{~m}^{2}$ for each image frame. The camera produced $1024 \times$ 1024-pixel images, with each pixel covering $2.2 \mathrm{~mm}^{2}$ of rock wall. This resolution enables identification of specimens a few centimeters long, depending on the distinctness of their morphological characteristics.

In order to obtain a $50 \%$ overlap, we calculated that the velocity would theoretically be limited to $0.2 \mathrm{~m} \mathrm{~s}^{-1}$. Heading deviations resulted in overlap variations, and to compensate for this, the speed was lowered to $0.15 \mathrm{~m} \mathrm{~s}^{-1}$. The vertical line spacing was one meter, providing a sidelap of $34 \%$. The theoretical data collection efficiency was $800 \mathrm{~m}^{2} \mathrm{~h}^{-1}$ for this arrangement. The photo mosaic in

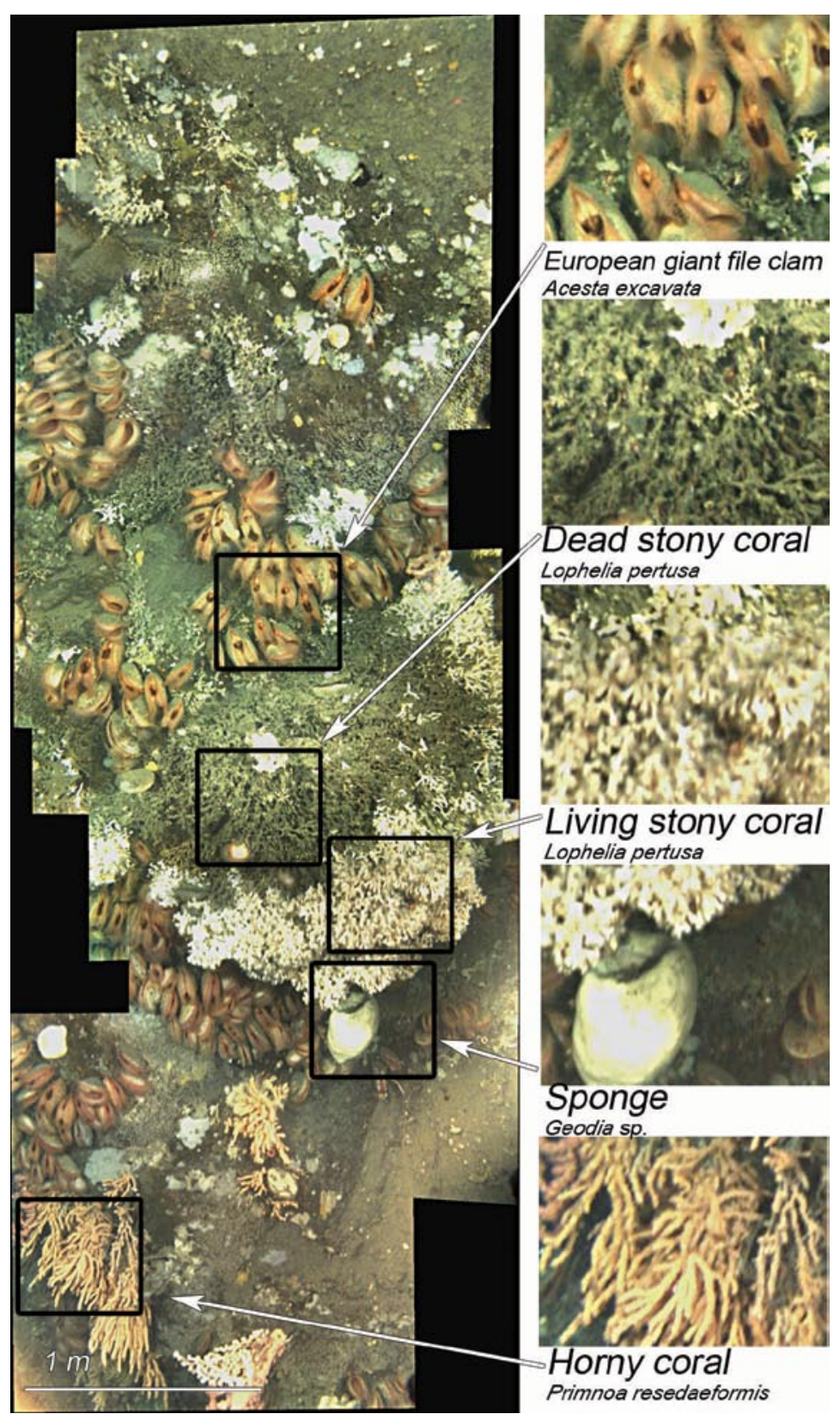

Figure 3. Photo mosaic with different taxa of benthic filter feeders growing on a vertical wall at $430 \mathrm{~m}$ depth in the fjord of Trondheim, Norway. Living stony corals appear white. Dead stony corals appear grey due to loss of antibacterial mucus production and consequent silt sedimentation. The area covered by the photo mosaic in the left image is approximately $2 \mathrm{~m} \times 5 \mathrm{~m}$. 
Figure 3 is made from nine images, while the photo mosaic in Figure 4 is constructed from 73 images.

\section{Marine Archaeological Survey}

To cover the complete wreck site, the WROV was maneuvered along eleven 50-m-long survey lines in a lawn-mower pattern by the closed-loop control system. The camera altitude was approximately $1.9 \mathrm{~m}$ to ensure sufficient lighting and area coverage of $1.6 \times 1.6 \mathrm{~m}$. A line spacing of $1 \mathrm{~m}$ resulted in $36 \%$ sidelap. Approximately 550 images were used in the resulting photo mosaic shown in Figure 5. Due to varying current conditions at the site, it was difficult to keep the vehicle velocity constant and hence the velocity was kept lower than the theo- retical $0.36 \mathrm{~m} \mathrm{~s}^{-1}$ to ensure overlap.

In the data set collected with the WROV installed in the excavation support frame (Figure 2), the vehicle was moved in a in a parallel or back-andforth, lawn-mower pattern with $0.5 \mathrm{~m}$ line spacing. The distance between each image along track was also $0.5 \mathrm{~m}$. The altitude varied from $1.5-1.7 \mathrm{~m}$ due to an excavated pit in the middle of the area. The resulting overlap and sidelap were close to $50 \%$. The large sidelap enabled photogrammetry processing of the images. A total of 270 images were included in the photo mosaic in Figure 6.

\section{Digital Image Processing}

Image light-pattern corrections, topology estimation, and blending were completed in automated Matlab-based software routines developed at Woods Hole Oceanographic Institution (Singh et al., 2007). Image topology estimation and image blending were performed by Intergraph software I/RAS C when manual intervention was necessary.

\section{Light-Pattern Corrections}

Even with proper light sources and camera setup, the image data set normally benefits from digital adjustments of light patterns. Light on an artificially lit underwater scene consists of an illumination component and a reflectance component. The illumination component is caused by the excitation of light on the area of interest. Illumination intensity usually varies gradually over

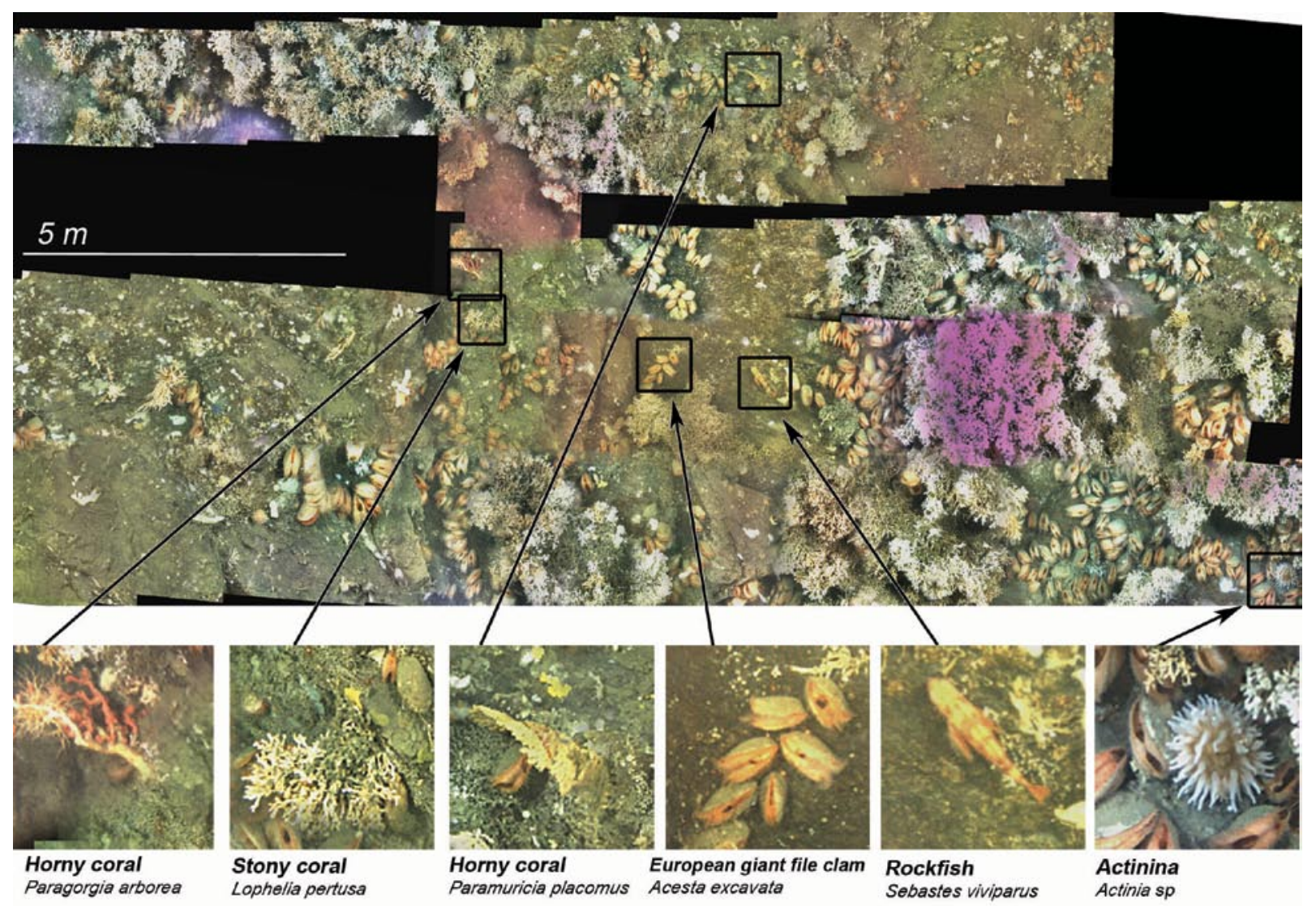

Figure 4. Photo mosaic of benthic filter feeders attached to the vertical rock wall in the ford. This site is at 390-m depth and dominated by corals and bivalves. The area covered by the photo mosaic is approximately $8 \mathrm{~m} \times 18 \mathrm{~m}$ and consists of 73 images. 
the area captured by the camera because of the geometry of the reflector, characteristics of the light-source lenses, and the distance from the light source to the depicted seabed. The reflectance component consists of the light reflected by the different objects in the image and usually varies more strongly than the illumination. The reflectance naturally depends on color, surface roughness, and inclination of the target of interest in the image. Hence, the illumination component and reflectance component of an image can be separated in the frequency domain. When the illumination component of the image is identified, it is modeled by surface fitting and corrected by enhancing dark areas and reducing bright areas

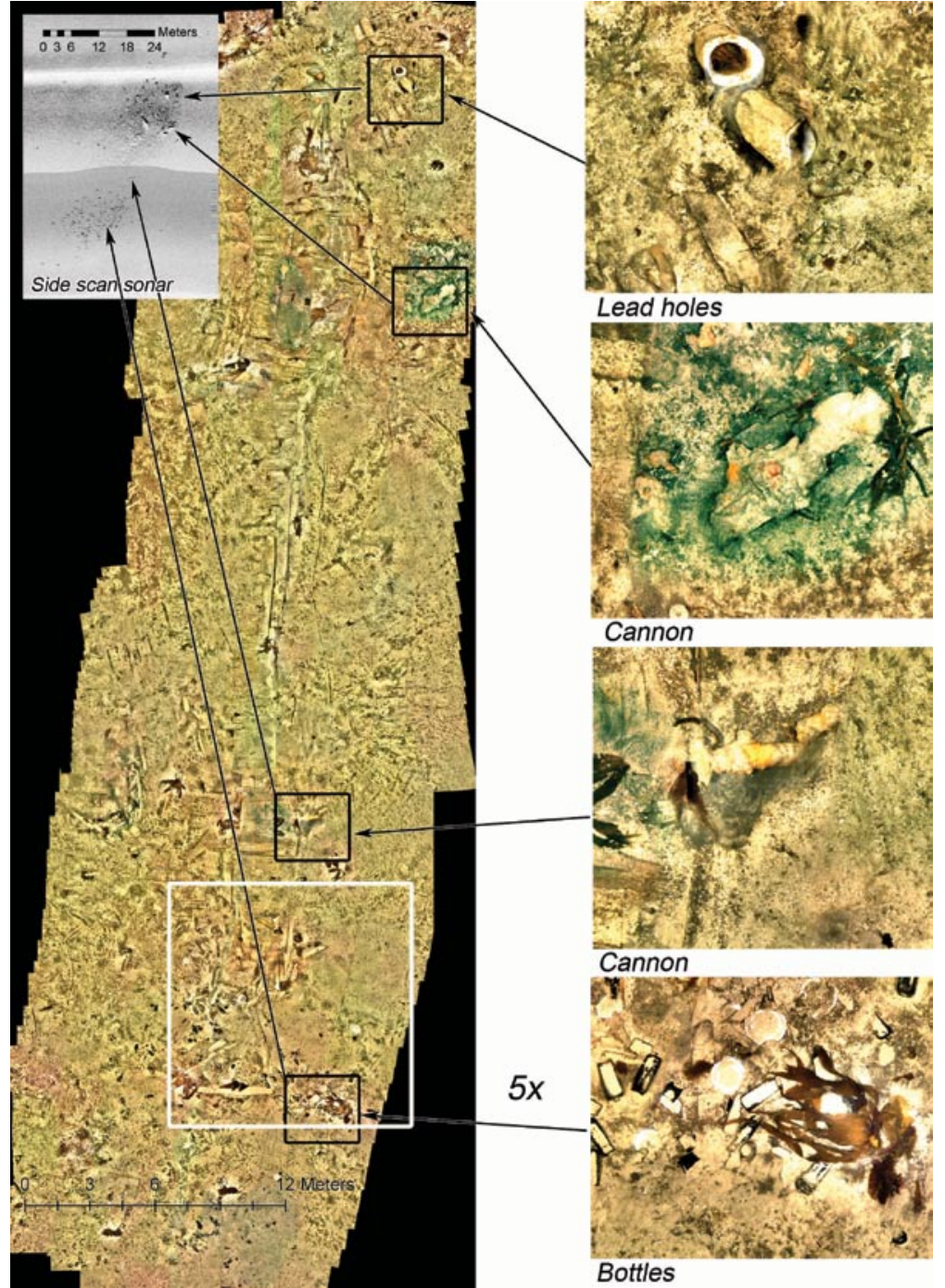

Figure 5. Shipwreck at $170 \mathrm{~m}$-depth. The four squares are magnified five times to show the level of detail in the mosaic. The area covered by the photo mosaic is approximately $19 \mathrm{~m} \times 37 \mathrm{~m}$, and the photo mosaic is compiled from approximately 550 images. The white square indicates the approximate position of the excavation support frame in Figure 2, and the area within the square corresponds to the area in Figure 6 . Note the kelp (Laminaria sp.) visible in the lower right image. Kelp does not live at this depth in these waters, so kelp seen at the wreck site must have been washed free from the substrate at shallower depth by heavy weather and transported by a current. to ensure even illumination before illumination and reflectance are merged to form a uniformly lit image. More details and illustrated examples can be found in Singh et al. (2007).

\section{Topology estimation}

The topology of an image pair consists of their relative positions, orientations, and scales. In all the case examples, the topology estimation process was based on feature recognition. Features occurring in an image pair are identified and recognized in both images to calculate the topology.

The interest points are edges and corners detected by calculating the autocorrelation of the second moment matrix of small image patches according to the method described by Harris and Stephens (1988).

Once the interest points are established, a Zernike moment is calculated for each interest point to provide it with a unique identity or tag. The Zernike moment $\left(A_{n m}\right)$ can be calculated according to the following equation:

$A_{n m}=\frac{n+1}{\pi} \sum_{x} \sum_{y} f[x, y] V_{n m}^{*}(x, y), x^{2}+y^{2} \leq 1$

where $f[x, y]$ represents an image patch surrounding the interest point, $V_{n m}^{*}$ represents the Zernike polynomial for the image patch, $n$ is the order of the polynomial, and $m$ is the number of repetitions for deriving the Zernike polynomial. The Zernike moment is a dependant of the image patch; hence, image patches showing the same feature will have similar Zernike moments. More details on Zernike moments can be found in Khotanzad and Hong (1990). By requiring the spatially coincident interest points to match, the relative position, rotation, and scale of an image 


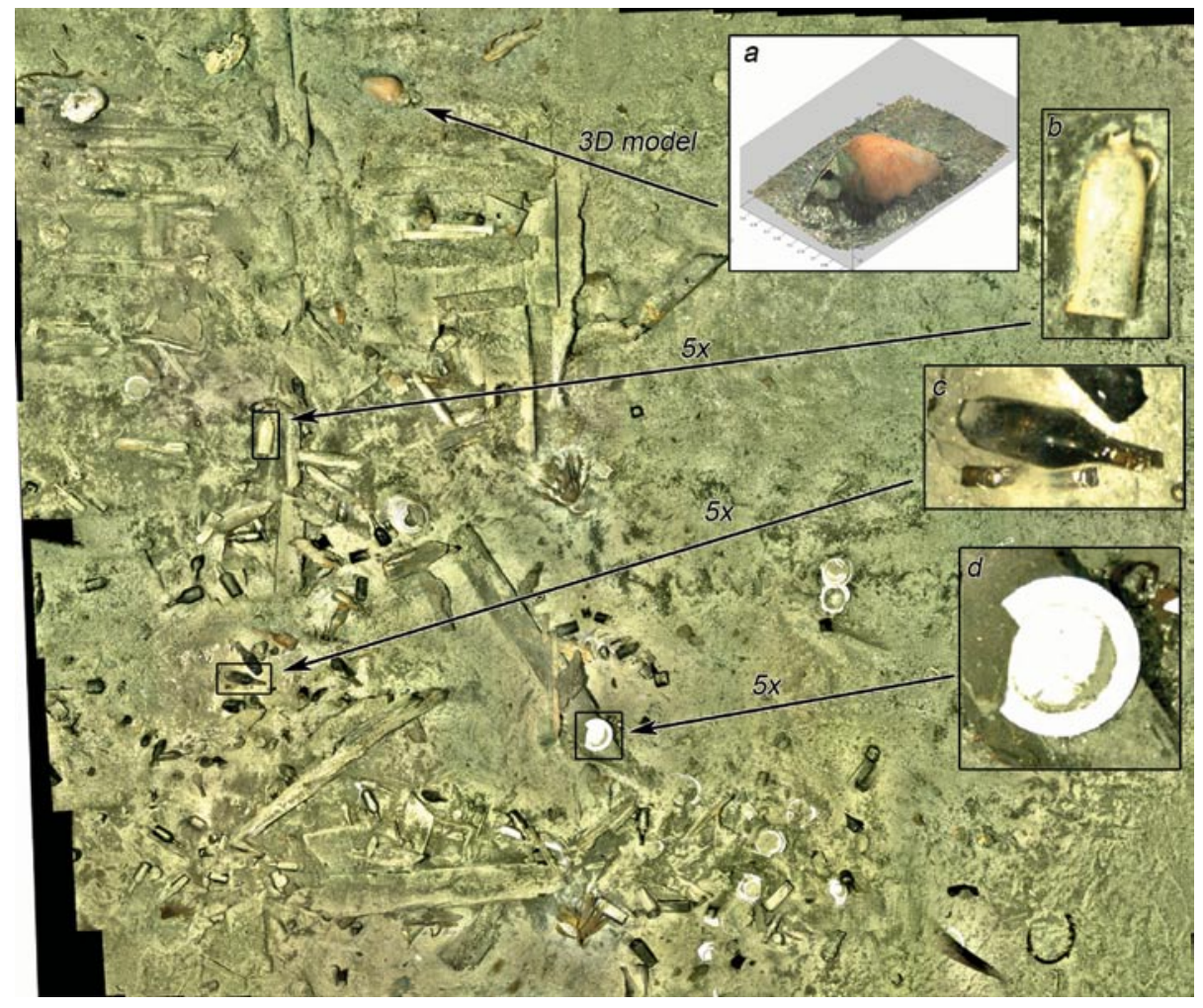

Figure 6. Detailed photo mosaic made inside the excavation support frame seen in Figure 2. Part (a) illustrates how the data set can be processed in three dimensions to measure the topography of the site. Insets (b), (c), and (d) demonstrate how the mosaic can be zoomed to reveal details of the artifacts observed. The photo mosaic is compiled from 270 images.

relative to the next image can be calculated (Pizarro, 2003).

For the data set acquired within the excavation support frame at the marine archaeology site, the processing was extended to include three-dimensional processing by means of navigation data. The three-dimensional positions of interest points were calculated to obtain a detailed bathymetrical model of the site. The method is described in Ludvigsen et al. (2006).

\section{Image Blending}

To make the mosaic appear seamless, it is necessary to avoid steps in image intensity on the borders between the images. After the topology has been estimated, intensity steps are reduced by merging the images in a process called blend- ing (based on Burt and Adelson, 1983). In the first step of the blending process, the original images are decomposed in the frequency domain using band-pass filters to form several frequency component images. These images are then merged over transition zones within the overlay areas of the neighboring images. The center of this transition zone is a line in the middle between the centers of the images. The resulting pixel intensity in each frequency-component image in the transition zone is determined by applying a weighted average of the overlapping images. To remove the border between two images, the average is weighted by the distance to the center line of the transition zone.

A mosaic is built for each frequency component before they are joined in the final step of the blending procedure. By choosing a narrow transition zone for the high-frequency components, and a wider transition zone for the lowerfrequency components, double appearance of smaller objects is avoided, while the larger structures in the initial image set are merged smoothly; the resulting mosaic thus appears seamless.

\section{RESULTS}

Marine Biological Example

The area shown in Figure 3 is located at $430-\mathrm{m}$ depth and is approximately 2-m wide and 5-m high. The temperature was $8.1^{\circ} \mathrm{C}$ and salinity was $35 \mathrm{psu}$ at the site. It is exposed to the Norwegian coastal current (Sakshaug and Sneli, 2000), and high abundance of zooplankton was observed at the site. The photo mosaic shows a benthic filterfeeder community comprised of benthic cold-water corals, bivalves, sponges, and numerous other taxa. Abundant horny corals like the Paragorgia arborea and Paramuricia placomus are attached to the exposed rock wall. The dominant species are the stony coral Lophelia pertusa and the European giant file clam Acesta excavata. The bivalve appears in large numbers, found in high density on the rock wall beneath the hanging stony coral branches. Both living and dead stony corals are visible. Mucus containing antibiotic compounds, which also removes sediment and particles (Mortensen, 2000), makes living stony corals look "clean and white." Dead stony coral, in which mucus production has ceased, is grey and brown due to sediment accumulation, microfauna attachment, and invasion by boring sponges.

The horizontal extent of the area shown in Figure 4 is approximately $18 \mathrm{~m}$ and the vertical extent is about $8 \mathrm{~m}$. The 
depth is about $390 \mathrm{~m}$. At this site, horny corals, stony corals, bivalves, rockfish, and actinia are among the most detectable taxa. Large branches of stony corals are attached to the vertical wall, and again both dead and living corals are distinguishable. The bivalves reside in clusters both on exposed rock and at sites protected by stony coral branches.

The taxonomic diversity on the vertical rock wall appears to be remarkably high compared to other habitats at the same depth in the study region. Due to the near-vertical inclination, sediment does not accumulate on the rock wall, which can be advantageous for many filter feeders. A reduced risk of being buried by sediment or marine snow may be favorable for larval settlement and for slowly growing organisms. For the larger mobile biota, attached taxa, such as corals, represent shelter.

\section{Marine Archaeological Example}

The photo mosaic in Figure 5

shows a shipwreck at approximately 170-m depth. The area depicted was approximately $37-\mathrm{m}$ long and 19-m wide. The wreck is eroded and most of the wood is decomposed, but the lower part of the wooden hull remains. The photo mosaic was produced for post-investigation documentation of the site before the investigation was closed. Two cannons, four lead cable holes, a large number of bottles, and the wooden remnants of the hull are the most distinct objects in the photo mosaic. The keel line is visible and indicates that the bow was probably located close to the leaden cable holes, while the stern was near the bottles. From observation of the wreck site and the artifacts recovered, archaeologists estimate that the wreck is most likely a merchant ship that was involved in trade between Europe and Russia. It probably sank in the early 1800s (Søreide and Jasinski, 2005).

The Figure 6 photo mosaic illustrates the wreck site after $0-20 \mathrm{~cm}$ of sediment was removed by a suction unit mounted on the WROV. Inset (a) of Figure 6 shows a three-dimensional processed model of a mug in the site to elucidate how the geometry of objects can be reconstructed by photogrammetry. Insets (b), (c), and (d) illustrate how the photo mosaic can be magnified to reveal details of the site. The photo mosaic shows exposed wooden hull parts, bottles, bottle necks sticking out of the sand, dishes, mugs, and other artifacts from the ship. Bottle shapes include round and square; there are bottles made of glass, and bottles made of ceramic material. In the middle of the area, there are wooden planks remaining from the bottom and keel of the vessel.

\section{DISCUSSION}

Areas for Improvement

Two particular areas of photo mosaicking hold significant potential for improvement: image acquisition efficiency and geometrical distortions.

\section{Image Acquisition Efficiency}

Image acquisition efficiency associated with photo mosaics is low: only a few hundred square meters could be covered within the time available for the marine biological survey. More ROV time was available for the marine archaeological survey, resulting in a larger area covered.

To improve image acquisition efficiency, the images should cover a larger area of seabed or be taken at a higher frequency, or both. The area covered in each image can be extended by increasing the altitude of the camera above the sea- bed. More powerful light sources would probably allow longer distances between camera and subjects, resulting in larger coverage. Increasing the light intensity on a scene will induce a higher degree of backscattered light from particles in the water, reducing the contrast in the resulting images. A trade-off between light and contrast must therefore be sought. Minimizing the common volume of the camera field of view and the light cones by using narrow-beam-pattern light sources and a large distance between light source and camera will also reduce the backscatter problem (Jaffe, 1990).

To further increase data-acquisition efficiency, the imaging frequency must be increased. The imaging frequency of the setup presented in the examples was limited by data-transfer capacity. This issue can be solved with proper systems engineering. If strobes are applied, their recharge time will limit the imaging frequency and thereby the vehicle speed during image acquisition. Using constant light, the next speed limitation during data acquisition is the amount of propulsion power installed to overcome the drag forces working on the vehicle and its tether.

By using light sources with spectral properties that fit the light absorption spectra of seawater, the altitude can probably be increased further. In the future, spectral analysis of both applied illumination and seabed reflectance can result in quantitative color analysis, which has great potential for identifying the present seabed compounds (Kirk, 1994).

\section{Geometrical Distortions} and Corrections

In the marine biological example, the extents of the subjects along the image axis were large. This causes geometrical 
distortions when the three-dimensional topography is projected to two dimensions in the resulting photo mosaics. In Figures 3 and 4, the distortions can be seen as varying sizes of a feature, for example, the giant file clams. The low vertical relief in the marine archaeological example is beneficial, but some geometrical errors are nevertheless seen along the keel line of the shipwreck in Figure 5. The keel line is actually straight, though it appears slightly curved in the photo mosaic.

Camera calibration reduces distortions originating from imperfections in the camera and is the first step toward increasing geometrical consistency in photo mosaics. Calibration can be performed either automatically or through a designated calibration procedure (e.g., Heikkila and Silven, 1997; Zhang, 1999). To further enhance the geometrical consistency of photo mosaics, mosaic processing and image matching should be done in three dimensions so that a fully three-dimensional scene can be extracted (Pizarro, 2003). This will require instrumentation on the underwater vehicle to measure the position and orientation of the camera for each image. Three-dimensional processing can be used to document the bathymetry of the site in high resolution. But, to reduce the geometrical distortions of a two-dimensional photo mosaic, the three-dimensional scene could be used to reproject the images into a twodimensional scene.

\section{Quality Control}

To increase the integrity of the information in photo mosaics, a procedure for quality control should be established. The simplest way to do this would be to physically place a linear scale bar in the imaged area and compare the dimension and shape of the scale bar with the known values.

Measuring the quality of the topology estimate represents a more sophisticated quality control (Pizarro, 2003). The quality of the topology estimate can be quantified by determining the amount and precision of matching interest points used in the resulting topology. The topology estimate can also be controlled by closed loops if the survey track crossed itself and a part of the seabed is imaged by different sections of the survey track (Fitzgibbon and Zisserman, 1998).

\section{Alternative Survey Methods}

Other high-resolution documentation methods are available for biological and archaeological research surveys. Laser line scanners, available since the early 1970s (Funk et al., 1972), are effective and produce clear images, but the resulting imagery is monochrome and less detailed than images from optical cameras. Interesting for biologists, the laser line scanner can be used to record fluorescence to measure, for example, the presence of chlorophyll at a site (Jaffe et al., 2001). The most important disadvantages of laser line scanners are, however, complexity, availability, and price. Few models are designed, and few units have been produced.

High-frequency side-scan sonars or acoustical cameras can also perform comprehensive site documentation. In contrast to optical imagery, sonars are not dependent on seawater visibility. The resolution of sonar imagery is increasing as technology develops but is not yet comparable to optical imagery. However, there is information in an acoustical signal about the return intensity and phase, which provides information on targets' hardness or surface roughness. Hence, sonars complement more than compete with optical image mosaicking. In Figure 5, a side-scan sonar image of the wreck site is inserted in the upper lefthand corner and can be directly compared to the photo mosaic to illustrate differences in coverage and details. The main characteristics of the site are recognized in both the Figure 5 sonogram and in the photo mosaic. More site details can be perceived from the photo mosaic than from the sonogram.

Video is the most likely alternative to photo mosaics. To cover an area larger than one video frame, the camera is moved and a virtual map is constructed in the mind of the viewer. The motion of the video camera can enhance understanding of a recorded object, as the object can be seen from different angles. But video is more complicated to communicate and present than a photo mosaic and the virtual map can vary between viewers.

\section{CONCLUSION}

Detailed site investigations may become more important in the future. Surveys like the biological example presented here can be useful for documenting damage caused by bottom trawling and other fishing methods (Fosså et al., 2002). Stony corals may become useful as climate markers because a climateinduced reduction of $\mathrm{pH}$ levels in the ocean is likely to degrade their aragonite skeletons (Sinclair et al., 2006). Photomosaic documentation and time-series analyses could thus be used to document changes in coral structures induced by the increased level of carbon dioxide in the atmosphere. Greater intensity in underwater construction work in the offshore petroleum industry, for example, 
may induce a larger demand for photo mosaics for underwater archaeological investigations. Documentation of the extent and details of illegal dumping is another potential application.

Photo mosaicking is a useful tool for illustrating small- and medium-sized underwater scenes of known extent. With the present methodology, one can expect a single photo mosaic to cover up to a few thousand square meters of seabed. For larger areas, the disadvantages of geometrical distortions and low dataacquisition rate prevent geospatially correct images. Usually, it would be sensible to compromise resolution and obtain a coarser search with sonar.

To our knowledge, neither the filter -feeder communities documented in Figures 3 and 4 nor the wreck site shown in Figures 5 and 6 could have been documented to the same level of detail by other methods. In Figures 3 and 4, we can characterize the filter-feeder habitat by the most dominant taxa, the type of seabed, and the co-existence among species. The photo mosaics of the archaeological site reveal the condition, position, and orientation of a large number of historical artifacts that together outline the size, approximate age, and type of shipwreck. The characteristics of the wreck site can be perceived within a few seconds from the photo mosaics. It would take hours to obtain the same level of understanding and knowledge of a site by means of single images or video. 四

\section{REFERENCES}

Ballard, R.D. 1975. Photography from a submersible during project FAMOUS. Oceanus 18(3):40-43.

Ballard, R.D. 1987. The Discovery of the Titanic. Warner/Madison Press, Toronto. 230 pp.

Ballard, R.D., A.M. McCann, D. Yoerger, L.L. Whitcomb, D.A. Mindell, J. Oleson, H. Singh, B. Foley, J. Adams, and D. Piechota. 2000. Discovery of ancient history in the deep sea using advanced deep submergence technology. Deep-Sea Research, Part 1 47(9):1,591-1,620.

Burt, P.J., and E.H. Adelson. 1983. Multi-resolution splining using a pyramid image representation. ACM Transactions on Graphics 2(4):217-236.

Eustice, R. 2005. Large area visually augmented navigation for autonomous underwater vehicles. Ph.D. Dissertation, MIT/WHOI Joint Program in Oceanography/Applied Ocean Science and Engineering, Woods Hole, MA.

Fitzgibbon, A.W., and A. Zisserman. 1998. Automatic camera recovery for closed or open image sequences. Lecture Notes in Computer Science 1,406:311.

Fosså, J.H., P.B. Mortensen, and D.M. Furevik. 2002. The deep-water coral Lophelia pertusa in Norwegian waters: Distribution and fishery impacts. Hydrobiologia 471:1-12.

Funk, C.J., S.B. Bryant, and P.J. Heckman. 1972. Handbook of underwater imaging system design (TP-303). Ocean Technology Department. Naval Undersea Center, 92 pp.

Gracias, N., and J. Santos-Victor. 2001. Underwater mosaicking and trajectory reconstruction using global alignment. Pp. 2,557-2,563 in Proceedings of OCEANS 2001, Honolulu, Hawaii, November 5-8, 2001, Volume IV, Marine Technology Society and Institute of Electrical and Electronics Engineers.

Harris, C.G., and M. Stephens. 1988. A combined corner and edge detector. Pp. 147-151 in Proceedings of The Fourth Alvey Vision Conference, August 31 - September 2, 1988, Manchester.

Heikkila, J., and O. Silven. 1997. Four-step camera calibration procedure with implicit image correction. Pp. 1,106-1,112 in Proceedings of the 1997 IEEE Computer Society Conference on Computer Vision and Pattern Recognition, Jun 17-19 1997, San Juan, PR, USA.

Jaffe, J. 1990. Computer modeling and the design of optimal underwater systems. IEEE Journal of Oceanic Engineering 15(2):101-111.

Jaffe, J., K.D. Moore, J. McLean, and M.P. Strand. 2001. Underwater optical imaging: Status and prospects. Oceanography 14(3):66-76.

Jerosch, K., A. Ludtke, M. Schluter, and G.T. Ioannidis. 2007. Automatic content-based analysis of georeferenced image data: Detection of Beggiatoa mats in seafloor video mosaics from the Haakon Mosby Mud Volcano. Computers and Geosciences 33(2):202-218.

Khotanzad, A., and Y.H. Hong. 1990. Invariant image recognition by Zernike moments. IEEE Transactions on Pattern Analysis and Machine Intelligence 12(5):489-497.

Kirk, J.T.O. 1994. Light and Photosynthesis in Aquatic Ecosystems, 2nd ed. Cambridge University Press, Cambridge, 509 pp.

Ludvigsen, M., H. Singh, and R. Eustice. 2006. Photogrammetric models in marine archaeology. In: Proceedings of OCEANS 2006, Boston, Massachusetts, September 18-21, 2006. Marine Technology Society and Institute of Electrical and Electronics Engineers.
Mortensen, P.B. 2000. Lophelia pertusa in Norwegian waters: Distribution, growth, and associated fauna. Ph.D. Dissertation, Department of Fisheries and Marine Biology, University of Bergen, Norway.

Pizarro, O. 2003. Large area underwater mosaicing for scientific applications. Ms.C. Dissertation, MIT/ WHOI Joint Program in Oceanography/Applied Ocean Science and Engineering, Woods Hole, MA. Sakshaug, E., and J.O. Sneli, eds. 2000.

Trondheimsfjorden. Tapir, Trondheim, Norway, 336 pp. [In Norwegian]

Sinclair, D.J., B. Williams, and M. Risk. 2006. A biological origin for climate signals in corals: Trace element "vital effects" are ubiquitous in Scleractinian coral skeletons. Geophysical Research Letters 33(17): L17,707.

Singh, H., J. Howland, and O. Pizzaro. 2004a. Advances in large-area photomosaicking underwater. Journal of Oceanic Engineering 29(3):872-886.

Singh, H., R. Armstrong, F. Gilbes, R. Eustice, C. Roman, O. Pizarro, and J. Torres. 2004b. Imaging coral habitats with the SeaBED AUV. The Journal for Subsurface Sensing Technologies and Applications 5(1):25-42.

Singh, H., C. Roman, O. Pizarro, R. Eustice, and A. Can. 2007. Towards high-resolution imaging from underwater vehicles. International Journal of Robotics Research 26(1):55-74.

Søreide, F., and M.E. Jasinski. 2005. Ormen Lange: Investigation and excavation of a shipwreck in 170-m depth. Pp. 2,334-2,338 in Proceedings of OCEANS 2005, Washington DC, September 18-23, 2006, Volume III. Marine Technology Society and Institute of Electrical and Electronics Engineers.

Vincent, A.G., N. Pessel, M. Borgetto, J. Jouffroy, J. Opderbecke, and V. Rigaud. 2003. Real-time georeferenced video mosaicking with the MATISSE system. Pp. 2,319-2,324 in Proceedings of OCEANS 2003, San Diego, California, September 22-26, 2006, Volume IV. Marine Technology Society and Institute of Electrical and Electronics Engineers.

Xu, X., and S. Negahdaripour. 1997. Vision-based motion sensing for underwater navigation and mosaicing of ocean floor images. Pp. 1,412-1,417 in Proceedings of OCEANS 1997, Halifax, Nova Scotia Canada, October 6-9, 200,6 Volume II. Marine Technology Society and Institute of Electrical and Electronics Engineers.

Zhang, Z. 1999. Flexible camera calibration by viewing a plane from unknown orientations. Pp. 666-679 in Proceedings of the 1999 7th IEEE International Conference on Computer Vision (ICCV'99), September 20-September 27, 1999, Kerkyra, Greece. Institute of Electrical and Electronics Engineers. 